\title{
MUDANCCAS NO MUNDO DO TRABALHO E O NOVO DISCURSO PEDAGÓGICO DO CAPITAL
}

Francisco José Lima Sales ${ }^{1}$

\section{CHANGES IN THE LABOR WORLD AND THE NEW PEDAGOGICAL SPEECH OF THE CAPITAL}

\section{RESUMO}

O presente trabalho tem como objetivo desenvolver reflexões sobre o novo discurso pedagógico do capital. Oriundo das transformações ocorridas no mundo do trabalho, geradas pela introdução das inovações tecnológicas e organizacionais na produção, tal discurso ao defender que a moderna produção provocaria o alargamento das qualificações, passou a exigir uma política educacional que promovesse a educação básica, bem como novas oportunidades de formação continuada, capaz de alargar cada vez mais o leque de possibilidades de qualificação profissional dos trabalhadores.

PALAVRAS-CHAVE: Mundo do Trabalho - Educação Básica - Qualificação Profissional.

\begin{abstract}
The present work has the objective of developing reflections on the new pedagogical speech of the capital. Originated in the transformations occurred in the labor world, generated by the introduction of the technological and organizational innovations in the production, that speech when defending that the modern production would broaden the qualifications, started demanding an educational policy that promoted the basic education, as well as new opportunities of continuous educational programs, able to increase even more the possibilities in the workers' professional skills.
\end{abstract}

KEYWORDS: Labor World - Basic Education - Professional Qualification.

\section{INTRODUÇÃO}

O novo discurso sobre a necessidade de níveis mais elevados de educação básica e profissional para fazer frente à nova realidade capitalista, repercutiu em países economicamente heterogêneos, como os da América Latina, na medida em que estaria condicionado a existência de um setor dinâmico, correspondente aos dos países centrais. Na periferia, o setor moderno tenderia a difundir o novo discurso àqueles setores tradicionais da 
economia, da mesma forma que, nos países avançados, as inovações organizacionais e as exigências de escolarização/qualificação - restritas igualmente a alguns ramos e setores - tenderiam a se propagar pelos setores que não introduziram tais estratégias.

Todavia, há diferenças importantes entre as economias avançadas e as periféricas, uma vez que, nos países centrais, a heterogeneidade ocasionada pela adoção do novo paradigma produtivo-organizacional seria precedida por uma elevada homogeneização da estrutura econômica; enquanto nos países periféricos, historicamente marcados por uma baixa homogeneização dessa estrutura, a nova heterogeneidade que se seguiria à modernização do setor mais dinâmico se agregaria à já tradicional heterogeneidade estrutural, que sempre caracterizou tais nações, como o Brasil.

A tendência observada acima tendeu a repercutir com mais intensidade nos países periféricos, pois o desemprego que se seguiu ao processo de reestruturação do capital teria atingido desde trabalhadores portadores de qualificação obsoleta - aqueles que não conseguem se adaptar às eventuais mudanças na tecnologia empregada -, até os portadores de maiores níveis de qualificação - aqueles que, no passado, foram beneficiados com amplas possibilidades de mobilidade social a partir da ampliação das oportunidades educacionais e do emprego formal (POCHMANN e BORGES, 2002 e POCHMANN, 2002). Do ponto de vista do mercado de trabalho, a novidade apresentada pelas novas formas do fenômeno de inclusão/exclusão do mercado de trabalho seria, então, a natureza qualificada da força de trabalho eliminada do setor moderno.

Nessa perspectiva, para os que passaram a fazer parte do moderno exército de reserva abrir-se-iam a contraditória possibilidade de inserção nas quase sempre penosas estratégias de sobrevivência, desenvolvidas no rol das atividades informais. Isso porque, se, por um lado, a inserção na informalidade restringia as possibilidades de reprodução da força de trabalho, por outro, a libertaria, na medida em que tornaria os excluídos do mercado formal donos do seu tempo e os únicos responsáveis pela sua atividade, lançando-os ao mesmo 
tempo diante de grandes riscos, mas, também, segundo o discurso dominante, possibilitando a ampliação de novas chances.

Apesar de as inovações tecnológicas e mudanças organizacionais apontarem para uma maior segmentação dos trabalhadores e para uma crescente insegurança do emprego, se observou o surgimento de um discurso de ressignificação do sistema educacional, que passou a clamar por uma educação básica e profissional flexível e polivalente, ou seja, pela valorização de uma educação que contribuísse "para a formação de um novo trabalhador, com novas e maiores habilidades para o exercício de diferentes tarefas e para - relacionamento lógico com informações atualizadas continuamente" (POCHMANN, 2002, p. 51).

Aos trabalhadores e aos indivíduos que teriam uma chance no mercado formal de trabalho seria exigida uma educação de caráter abrangente, geral e abstrata, ou seja, uma formação capaz de desenvolver competências, consideradas fundamentais, tais como a criatividade, a autonomia, o desenvolvimento do pensamento divergente e da capacidade de comunicação etc. Todavia, a idéia força é que não somente os inseridos ou os que teriam chances de adentrar o mercado formal fossem contemplados, mas toda a população, mesmo aquela possivelmente excluída ou com menores chances de adentrar o mercado de trabalho, que tenderia a ser absorvida pelo mercado informal.

O interesse do capital pela educação dos trabalhadores se explicaria pela mudança do paradigma produtivo que exigiria a substituição de uma formação pautada na qualificação específica por outra fundada na qualificação geral. Essa mudança de paradigma educacional visaria, antes de tudo, à formação de competências mais apropriadas ao moderno modelo técnicoorganizacional, visando à empregabilidade do trabalhador.

Para Bruno (1995), as novas exigências passariam a gravitar em torno da posse de competências, classificada pela autora em três diferentes tipos: (i) competências de educabilidade (capacidade de aprender a aprender); (ii) competências relacionais; e, (iii) competências técnicas básicas ligadas aos diferentes campos do conhecimento. Tais competências deveriam possibilitar o desenvolvimento de capacidades sócio-comunicativas, de modo à 
instrumentalizar os trabalhadores no trabalho cooperativo (em equipes), bem como na produção de conhecimentos ampliados que possibilitassem a independência profissional.

Para se alcançar esse objetivo, seria

[...] especialmente valoradas qualificações manuais e intelectuais que atende[sse]m as necessidades da vida diária, com caráter polivalente, enquanto qualificações artesanais s[eriam] requeridas não apenas para o desenvolvimento de atividades independentes mas também para novas formas de inserção parcial ou intermitente no mercado (por exemplo, trabalho por encomenda) que escapam às formas tradicionais do contrato. Ao trabalho flexível dever[ia] corresponder a flexibilização da atividade do indivíduo no decorrer de sua vida, a flexibilização de sua mente e de suas disposições de adaptação a situações novas e difíceis, a maior possibilidade de lidar com a insegurança e de montar mecanismos sociais e políticos para reduzi-la. O trabalho flexível exige um sistema de educação que prepare para enfrentar esta realidade e ofereça novos (outros) conhecimentos, ao lado da difusão de uma nova mentalidade (PAIVA, 1991, p. 89).

A flexibilidade educacional que corresponderia à flexibilidade do trabalho, por sua vez, somente seria conseguida por meio de uma formação abrangente, aberta a sucessivas adaptações, já que a flexibilização e a despadronização da produção que se seguiram à crise do taylorismo/fordismo, trariam, como conseqüência, a regressão do treinamento em serviço e a crescente formalização dos requisitos educacionais, ou seja, os recentes "requisitos profissionais, indispensáveis ao ingresso e à permanência no mercado de trabalho em transformação, seriam passíveis de atendimento somente por meio de um maior nível de educacional dos trabalhadores" (POCHMANN, 2002, p. 41).

O novo discurso do capitalismo sobre a educação, ao defender que a moderna produção provocaria o alargamento das qualificações, passou então a exigir uma política educacional que promovesse a formação geral, bem como novas oportunidades de educação continuada, capaz de alargar cada vez mais o leque de possibilidades de qualificação dos trabalhadores. 


\section{A RELAÇÃO ENTRE EDUCAÇÃO BÁSICA E QUALIFICAÇÃO PROFISSIONAL}

Nesse contexto, a escola básica e de caráter geral passou a ser considerada o único meio de atender à flexibilização, que passou a caracterizar o processo produtivo contemporâneo, uma vez que somente a posse de operações cognitivas mais amplas e de conhecimentos de base científicotecnológicos, desenvolvidas pela escolarização, poderia promover mais facilmente a adaptação dos trabalhadores, por meio da educação profissional em seus diferentes níveis, às difíceis condições do mercado de trabalho.

Na América Latina, diversos organismos internacionais ${ }^{2}$ já pregavam a necessidade da preparação dos recursos humanos para a reestruturação das economias da região, ou seja, esses organismos vinham prescrevendo o urgente aumento de escolaridade como condição para a adoção de novas tecnologias. A ênfase na educação básica, segundo um deles, a Cepal, cumpriria dois objetivos: a) elevar o nível de escolaridade dos trabalhadores; e b) dotar o trabalhador de uma base sólida de educação geral, condição necessária para maior treinabilidade em serviço e para programas de educação continuada, adaptando-os à flexibilidade e às crescentes mudanças no processo produtivo.

Com a flexibilização da produção e o requerimento de um novo perfil de qualificação, se exigiriam conhecimentos que, até então, foram escamoteados pelo capital. Daí, o interesse pela ampliação da escolarização básica, pois, uma vez presentes na força de trabalho, tais conhecimentos melhorariam a produtividade e, conseqüentemente, a produção econômica capitalista. A esse respeito, Carnoy (1992, p. 27) afirma que

[...] a melhor medida individual do impacto da educação básica sobre o desenvolvimento econômico, (...) é a maior produtividade dos trabalhadores (...) mais escolarizados em relação aos menos instruídos. Os indicadores da produtividade ilustram o efeito direto da educação sobre a capacidade de produzir e, portanto, sobre o potencial de aumentar a produtividade econômica.

No Brasil, essa tese foi endossada pela fração industrial da burguesia, que elegeu a educação como capital humano imprescindível ao 
aumento da produtividade e da competitividade da economia. As transformações tecnológicas das últimas décadas e os novos processos produtivos instalados estariam exigindo, cada vez mais, trabalhadores qualificados e capacitados. Por isto, e pelos efeitos benéficos que teriam sobre a realidade econômica e social, a educação deveria ser, mais do que nunca, a prioridade nacional.

Diferentemente do modelo anterior de exploração que entendia a educação como algo secundário no processo de qualificação - pois anteriormente se optava pelo treinamento específico do operário no próprio espaço da produção -, as mudanças em curso estariam a requerer um novo estilo de trabalhador, além da redefinição do papel das instituições escolares. O novo trabalhador necessitaria, atualmente, "de habilidades gerais de comunicação, abstração e integração, as quais não podem ser geradas rapidamente no próprio local de trabalho. São habilidades próprias de serem aprendidas na escola, durante a instrução regular" (FREITAS, 1993, p. 91).

A valorização da educação vinculou-se tanto ao fato de tentar inserir o Brasil, de forma mais competitiva, no mercado internacional quanto a uma concepção que estabeleceu uma ligação linear entre desenvolvimento econômico e educação, de modo que a educação passou a ser apresentada como o mais importante instrumento de promoção social para as camadas populares.

Partindo desse pressuposto, pode-se inferir que o novo padrão de reprodução e acumulação do capital, assentado na aplicação de novas tecnologias e em modelos de gestão da força de trabalho, impôs um mínimo de qualidade na educação da força de trabalho, à medida que essa preocupação pela educação indicava demandas efetivas por um trabalhador com uma nova qualificação que Ihes possibilitassem efetivar a reconversão tecnológica que os tornassem competitivos no embate da concorrência intercapitalista (FRIGOTTO, 1995).

No entanto, em que pese ser verdadeiro o fato de as possibilidades de inserção dos indivíduos no mercado dependerem da posse de uma gama de conhecimentos e competências que os habilitariam a competir pelos poucos empregos disponíveis, é igualmente verdadeiro que o desenvolvimento 
econômico atualmente não possibilita uma maior integração dos indivíduos a vida produtiva. Isso porque o crescimento das modernas economias pode comportar uma elevada taxa de desemprego, permitindo que setores consideráveis da população sejam alijados dos benefícios do crescimento da economia.

A tendência à ampliação do nível de escolarização pode não levar, também, a uma maior qualificação do trabalhador, uma vez que uma força-detrabalho capaz de ler, escrever, contar, enfim, com uma formação educacional mais sólida não implica, necessariamente, trabalhadores com mais qualificação profissional. Até porque, o manejo de um painel eletrônico pode diferir da operação de um equipamento convencional apenas no sentido de que no primeiro a tarefa seria ainda mais parcial, limitada e predeterminada do que no segundo caso. Em nenhum dos dois exemplos o trabalhador teria acesso real ao conhecimento da totalidade do processo de produção.

Ainda que não restem dúvidas de que à educação se colocaram novos problemas em função das transformações nas estruturas produtivas, a novidade seria que a educação profissional teria, como ponto de partida, a formação geral, ou seja, ela se assentaria em elevados níveis de educação formal, mais precisamente a educação básica. Todavia, à desobrigação do Estado em fomentar políticas de emprego que possibilitassem a inserção no mercado formal dos trabalhadores contemplados pelas políticas de educação, especificamente, as ações de educação profissional em nível básico, foi atribuída responsabilidade ao trabalhador pela sua condição de trabalho, individualizando a problemática do desemprego. Polivalência e multifuncionalidade, provenientes de uma educação mais geral e abstrata, fundada no novo modelo das competências, seriam então os atributos capazes de garantir a empregabilidade do trabalhador.

No Brasil, a baixa qualificação da força de trabalho, compreendida como um fator de atraso ou de impedimento do desenvolvimento econômico e a disposição em inserir o país no mundo globalizado, marcado pela competitividade, qualidade e produtividade, transformaram a educação dos trabalhadores num elemento central das políticas sociais do governo federal. Isso permite explicar o receituário de propostas no campo educacional, que 
buscava a constituição de um novo perfil de trabalhador, fundado nas noções de competências e de empregabilidade.

As particularidades do processo de reestruturação produtiva implantado no país, marcado, igualmente, pela incorporação de novos princípios de flexibilização do trabalho e da produção, fez emergir novas demandas educacionais aos trabalhadores, levando o governo Fernando Henrique Cardoso a eleger a qualificação profissional como um dos eixos principais das políticas de mercado de trabalho, utilizadas para enfrentar a crise do desemprego. Esse pressuposto, a despeito de todas as limitações existentes, foi aquele sobre o qual se fundamentou o Plano Nacional de Qualificação do Trabalhador (PLANFOR).

Nesse contexto, não resta, apenas, indagar sobre o papel reservado à escolarização e, em particular, à educação profissional, mas, igualmente e, sobretudo, acerca do papel cumprido pelas noções de empregabilidade e competência, já que do discurso que prega a reforma das estruturas educacionais, compatível com as exigências do mercado de trabalho, a desobrigação do Estado para com a geração de empregos e a responsabilização individual dos trabalhadores pelo desemprego emergeria uma iminente contradição.

\section{CONSIDERAÇÕES FINAIS}

Pensadas como estratégias de enfrentamento do desemprego, as ações de educação básica e profissional deveriam, antes, pressupor o desenvolvimento de uma política econômica favorável ao desenvolvimento econômico do país, aliadas às intervenções estruturais, como a reforma agrária, que poderiam favorecer a geração de renda e o crescimento do emprego padrão. Ou seja, dependeria, em última instância, de um projeto nacional que objetivasse a distribuição de renda e a promoção da inclusão social. Caso contrário, tais ações tendem a continuar pouco eficazes, mesmo enquanto políticas compensatórias, voltadas para atenuar somente os reflexos negativos do mercado de trabalho. 
A educação básica e profissional, evidentemente, não cria empregos, mas, quando articuladas às demais políticas de trabalho e renda, apoiada numa política de desenvolvimento que considere o social não como anexo do desenvolvimento econômico, mas, antes, seu alicerce, sem dúvida, se constitui em um importante instrumento para elevar o nível de vida da população brasileira.

No entanto, a lógica destrutiva que o capital historicamente firmou impõe a dúvida quanto à viabilidade de tais políticas em realidades como a brasileira, considerando que as determinações estruturais do capitalismo, ao restringirem cada vez mais o número de postos de trabalho, cria e recria, na informalidade, uma série de ocupações precárias que, embora sirvam a sobrevivência dessa população, longe estão de permitir um mínimo de dignidade aos trabalhadores.

\section{REFERÊNCIAS BIBLIOGRÁFICAS}

BRUNO, Lúcia (Org.). Educação, qualificação e desenvolvimento econômico. In: Educação e trabalho no capitalismo contemporâneo. Porto Alegre: Atlas, 1995.

CARNOY, Martin. Razões para investir em educação básica. New York, USA: UNICEF, 1992.

PAIVA, Vanilda. Educação permanente e capitalismo tardio. In: PAIVA, Vanilda e RATTNER, Henrique. Educação permanente e capitalismo tardio. São Paulo: Cortez: Autores Associados, 1985.

FREITAS, Luíz Carlos. Neotecnicismo e formação do educador. In: ALVES, Nilda (Org.) Formação de professores: pensar e fazer. 2. ed.

São Paulo: Cortez, 1993.

FRIGOTTO, Gaudêncio. A produtividade da escola improdutiva: um (re)exame das relações entre educação e estrutura econômico-social e capitalista. 4 ed. São Paulo: Cortez, 1993.

. Educação e a crise do capitalismo real. São Paulo: Cortez, 1995.

POCHMANN, Márcio, BORGES, Altamiro. "Era FHC": a regressão do trabalho. São Paulo: Anita Garibaldi, 2002. 
POCHMANN, Márcio. O emprego na globalização. A nova divisão internacional do trabalho e os caminhos que o Brasil escolheu. 2 ed. São Paulo: Boitempo Editorial, 2002.

1 Doutor em Educação. Professor na Universidade Federal do Maranhão. Email: chicodede@gmail.com.

2 Cepal (1990), Consejo Latinoamericano de Ciencias Sociales-Clacso (1992), Oficinas

Regional de Educação para a América Latina e Caribe (Orealc)/UNESCO (1992)

ARTIGO RECEBIDO EM 17.09.2010

ARTIGO APROVADO EM 29.10.2010 